\title{
Geothermal data analysis and optimization
}

\section{Robert McKibbin $^{1} \quad$ Neville Fowkes ${ }^{2} \quad$ Brendan Florio $^{3}$ Franklin G. Horowitz ${ }^{4}$}

(Received 28 October 2010; revised 19 January 2011)

\begin{abstract}
The possibility of convective upwelling in the sedimentary Perth Basin, based on available data and simple models, was examined and its relative contribution to heat transport in a geothermal context assessed. The presence of such upwelling could greatly increase the viability of geothermal power extraction from the Basin. The onset of convection is determined by the Rayleigh number, which provides a measure for the balance between buoyancy driven upwelling and viscous resistance to flow. Being sedimentary, the porous aquifer system is layered and fractured so that the effects of anisotropy, especially that in permeability, need to be accounted for when determining the critical Rayleigh number. Variations in viscosity and the coefficient of thermal expansion also occur within the convection zone. Estimates were made for the relative size of the convective contribution to heat transport. The possibility of the surface detection of cellular convection and the effects of horizontal inflow into the convection zone were examined.
\end{abstract}

http://anziamj . austms.org.au/ojs/index.php/ANZIAMJ/article/view/3600 gives this article, (c) Austral. Mathematical Soc. 2011. Published February 10, 2011. ISSN 1446-8735. (Print two pages per sheet of paper.) Copies of this article must not be made otherwise available on the internet; instead link directly to this URL for this article. 


\section{Contents}

1 Introduction

M2

1.1 Background . . . . . . . . . . . . . . M4

1.2 The group's progress . . . . . . . . . . . . . . . M5

1.3 Report structure . . . . . . . . . . . . . . M7

2 The geological setting

3 Some numbers $\quad$ M9

3.1 Well $\log$ constraints . . . . . . . . . . . . . . M9

3.2 Background and induced flows . . . . . . . . . . M10

4 Convective heat transfer in the aquifer $\quad$ M12

4.1 Convective instability . . . . . . . . . . . . . . M12

4.2 The isotropic model . . . . . . . . . . . . . . . M16

4.3 The anisotropic model . . . . . . . . . . . . . . M17

5 Detection of convection $\quad$ M21

6 Conclusions $\quad$ M31

A Nomenclature $\quad$ M32

$\begin{array}{ll}\text { References } & \text { M34 }\end{array}$

\section{Introduction}

The Western Australian Geothermal Centre of Excellence (WAGCoE), a WA government funded research collaboration between UWA, CSIRO and Curtin University, has been assessing the economic feasibility of extracting geothermal energy from the deep sedimentary Perth Basin. With this in mind, they have collected temperature, pressure, and other data from (groundwater and 
oil) boreholes in the area as well as examined remotely sensed observational data of ground surface temperatures. They examined possible technologies for harnessing this (low temperature) resource. Their observations and simulations suggest that convection may be occurring in the aquifer; this could radically change the temperature profile and thus significantly reduce drilling costs. The WAGCoE co-founder Frank Horowitz asked the MISG to investigate a range of issues associated with the extraction process to complement the Centre's work.

The 2010 MISG 'Geothermal' study group concentrated on problems of advective transport of heat in stratified geological units appropriate for the conditions found in the Perth Basin of Western Australia. The main hypothesis examined is that advective transport of heat is an important contribution to the overall heat transport. Sampled temperatures in the system indicate an approximate temperature increase through the main aquifers from about $40^{\circ} \mathrm{C}$ to $80^{\circ} \mathrm{C}$. Clearly conductive heat transport is present (as elsewhere over the Earth's surface), but we wanted to find out whether the system is susceptible to 'unforced' or natural convection.

There is a well developed theory in the fluid mechanics/porous media literature about the conditions required for convective instability in non-homogeneous permeable systems that are heated from below. The theory suggests that the onset of convection, as well as the resulting heat transfer, is determined by a single dimensionless combination of thermodynamic fluid and rock matrix transport parameters known as the Rayleigh number (denoted by Ra), with convection occurring if $\mathrm{Ra}$ exceeds a critical value $\mathrm{Ra}_{\mathrm{c}} \approx 40$. This was seen as relevant for our study, so we concentrated on using the available field data to determine whether supercritical conditions are present in the Perth Basin.

It is likely there is also an advective transport component due to a hydraulic gradient from a recharge zone (assumed as a first approximation to be at an elevated height in the Darling escarpment to the east) westwards to a discharge zone assumed to be offshore. An attempt was made to quantify this flow, as well as that which would result from reinjection of cooler fluid 
from an energy extraction plant of the future. However, for the purposes of most of our sub-problems, we neglected hydraulic gradient effects.

\subsection{Background}

Mostly we think of geothermal power generation in the context of volcanic zones (for example the Rotorua and Wairakei areas in New Zealand) where boiling water is expelled from the Earth and is used primarily for electricity generation. However, under favourable circumstances heat extraction from the Earth can be economically feasible under much less energy rich conditions using geothermally heated liquid from groundwater aquifers. The extraction temperatures are too low for electricity generation but the energy is sometimes used for passive heating, cooling, or other systems. Studies undertaken by WAGCOE indicated that it may be economically feasible to extract geothermal power from the deep (10 km thick) sedimentary Perth Aquifer Basin (Regenauer-Lieb et al. [9]). Of course there is available thermal energy at great depth, but it was thought that the temperature and rock matrix parameters of the Basin are such that convective upwellings may occur in the aquifer; these would transfer heat to shallower levels, substantially reducing the borehole depth required to access the heat source.

The envisaged heat extraction procedure is one whereby water from the aquifer would be pumped to the surface, some energy extracted in a heat exchanger, and then the water returned to the aquifer via a second borehole; this reinjection satisfies environmental concerns. It is hoped that drill holes at depths of the order of $2000 \mathrm{~m}$ would access water at about $80^{\circ} \mathrm{C}$ or above to be used for passive heating, cooling or desalination. The problem was presented by The Centre's co-founder Frank Horowitz, who asked the MISG Group to investigate a range of issues associated with the heat extraction process. However, the group ended up primarily concentrating on the convection issue with particular reference to the stratified and fractured geology found in the Perth Basin. 


\subsection{The group's progress}

First we considered a homogenized matrix system where the rock parameters were assumed uniform with average values estimated from the borehole cores. The calculated values of Ra exceeded the critical value only for (perhaps) unrealistic values of the system parameters. However, the lack of euphoria was briefly tempered by the thought that the layering of the system may influence the calculation. The group further determined from the theory that anisotropy of thermal conductivity and permeability of the matrix produces an estimate of the critical Rayleigh number that is different from that for a homogeneous system.

Anisotropy in the thermal conductivity theoretically increases the critical Rayleigh number; however, the conductivity of rocks varies very little, so the anisotropy in that parameter is negligibly different from unity. Anisotropy in permeability is induced by material layering. Geological strata necessarily induce a permeability that is, on average, greater in the bedding plane than perpendicular to it. What is more, such anisotropy generally reduces the (theoretical) critical Rayleigh number! Amidst some excitement, an assessment of this anisotropy (from a rather complicated set of rock core and borehole measurements) was made as a stratum thickness weighted average of intrinsic rock permeabilities, with the result that the horizontal value for permeability is about 4.6 times that in the vertical. These estimates reduced the critical Rayleigh number to 21.6, about half that computed from isotropic parameters. Immediately, we realised that conditions for convection may be met, even using the linearised theory with the lowest datum temperature $\left(40^{\circ} \mathrm{C}\right)$ for the linearised calculations.

In optimistic anticipation of such a result, a small group worked on how enhanced heat transfer in the Yarragadee Aquifer would manifest itself in the temperature distribution in the near surface superficial formations. This is a fairly standard problem in heat transfer, and quick progress was made. However, it was shown that there would be a very small signature at ground surface level, and instrumentation would have to be sensitive and widespread 
to obtain significant measurements. So, this encapsulated the problem overall: Even if there was a convective process at work, how would measurements be able to be made to detect the upflow and downflow regions? So, how could advantage be taken of the convection even if the Ra estimates were correct?

Over in UWA, the small 'at home' group was working. With the assumption that convection was occurring they trawled the literature for information about theoretical work on layering effects on cell size and the stability of such convection cells. The idea was that significant sub-layering caused by thick differently permeable strata might produce vertically aligned but largely separated co-rotating cells that, in tandem, would advect heat from the hot base to the surface. At the end of the week no firm conclusions had been reached.

Driven by concern that the thermodynamic properties of water were being approximated too severely in the linear stability theory, a numerical simulation of $2 \mathrm{D}$ rolls was made using a commercial computer package. Temperature variations in the aquifer result in significant changes in the viscosity and thermal expansion coefficient of water (factors two to three), so that it is not clear what datum to use for the effective Rayleigh number of the aquifer. Sensibly one would expect the mean temperature to be appropriate and linear stability theory to apply; however, to check this out a numerical simulation of $2 \mathrm{D}$ rolls was made using a commercial package. These simulations, which were completed post-MISG, confirmed the theoretical convection onset results and indicated that the primary effect of temperature variations is to marginally change the cell shape.

A late idea resulted from current work by one of the group members; it considers the possibility that longitudinal convection may be induced in a sloping aquifer by a near vertical temperature gradient. The warmer fluid near the bottom would move up-slope (in this case, towards the east) while the returning cooler fluid near the top moves down-slope. It was not clear how this would affect the possible exploitation, because the temperature profile would remain conductive, and only be altered by convective rolls as were already 
considered above. A small group of postgraduate students seized upon some aspects of this, and their efforts were rewarded by co-authorship of a paper (McKibbin et al. [6]). The enthusiasm to participate in this way reinforces the benefits of the MISG to engagement of postgrads in mathematical enquiry into useful applications.

\subsection{Report structure}

Section 2 describes the geological setting. Section 3 then describes some overall parameter estimates and methods for calculating them. Section 4 investigates theoretical models for thermally-driven (natural) convection in a permeable layer heated from below. Critical values of the dimensionless Rayleigh number are estimated by using aquifer matrix parameters deduced from well logs. In the event that such cells exist, Section 5 examines the detection of their presence at, or just below, the ground (using perhaps satellite data or shallow surface drilling). Section 6 concludes.

\section{The geological setting}

Rocks of the Perth Basin consist of multiple layers of sedimentary strata, where matrix (as opposed to fracture) hydraulic permeability is expected to be dominant. Immediately below the ground surface in the Perth metropolitan area there is an unconfined aquifer consisting of rocks geologically known as the 'superficial' formations, see Figure 1 for a schematic vertical section. This topmost aquifer is underlain by various shallow confined aquifers consisting of rocks of the Kings Park Formation (locally), the Leederville Formation, and the South Perth Formation. For convenience, since these rocks are not normally in hydraulic communication with the deeper and hotter aquifers, all of these aquifers were lumped together into a group labelled (perhaps confusingly to people familiar with the stratigraphy) as the 'superficial' units 
Surface

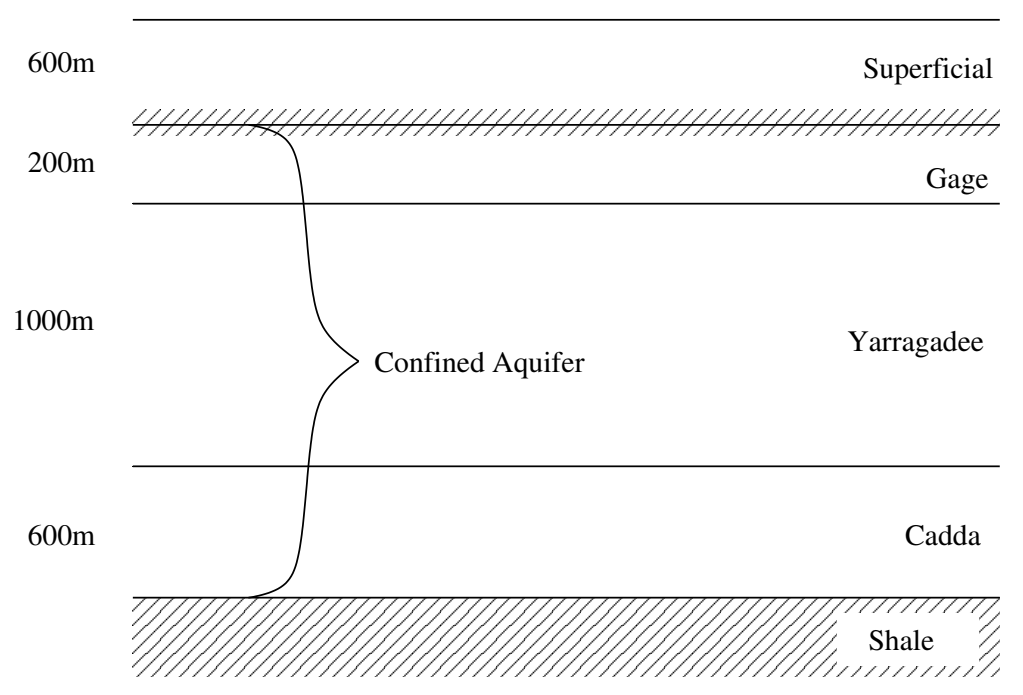

Figure 1: Schematic of the main geological structures in the Perth Basin.

and we basically ignored them (other than the boundary conditions they provide) in our models.

At a depth of about $600 \mathrm{~m}$, the top of a confined aquifer consisting of rocks from the Gage Formation is found. Those rocks are about $200 \mathrm{~m}$ thick, with uniform physical properties. Below the Gage, but in hydraulic communication with it, are rocks of the Yarragadee Formation. The contact between the two formations is an erosional unconformity, so the thicknesses of the two units vary with map position. The rocks of the Yarragadee are assumed to be about $1000 \mathrm{~m}$ thick, also with uniform physical properties. (These assumptions of uniform rock properties were relaxed in various ways in several of our subproblems.) Below the Yarragadee lie the rocks of the Cadda Formation, about $600 \mathrm{~m}$ thick, also in hydraulic communication with the Yarragadee. Indeed, in the groundwater community, rocks of all three formations (Gage, Yarragadee, and Cadda) are often called the "Yarragadee Aquifer". Below the Cadda Formation lie rocks of the Cattamarra Coal Measures. These rocks are 
shales, with interbedded sandstone layers. Hence we treat the basal contact of the Cadda with the Cattamarra as being a hydraulic seal.

The result is our basic model of three stratified layers, with physical properties internally uniform, all participating in a single hydraulically connected system $1800 \mathrm{~m}$ thick, overlain by the superficial layer about $600 \mathrm{~m}$ thick.

WAGCOE's estimates of temperatures in the system are an increase from about $40^{\circ} \mathrm{C}$ at the top of the Yarragadee Aquifer to about $80^{\circ} \mathrm{C}$ at its base. Hence we assume an average temperature of $60^{\circ} \mathrm{C}$ and a temperature gradient of about $25^{\circ} \mathrm{K} \mathrm{km}^{-1}$.

\section{Some numbers}

\subsection{Well log constraints}

The closest deep borehole to the sites of WAGCoE's proposed exploitation systems is the Cockburn Number 1 oil well. Cockburn 1 was drilled in 1967, to a total depth of 10020 feet $(3054 \mathrm{~m})$, with cores recovered from several discrete depths within the bore. Results of laboratory measurements of porosity, permeability, and other physical parameters of these cores are found in the Cockburn 1 Well Completion Report 1967 [1]. A digital copy of the wireline logs for Cockburn 1, sampled every six inches, is also available in Log Ascii Standard (LAS) format. Well logs that directly measure porosity were not available over the entire depth range in Cockburn 1. However, the porosity was estimated from the sonic interval velocity log (which does cover the entire depth range) using the Wyllie equation from petrophysics (Ransom [8]).

Fitting both a power law and an exponential relation between porosity and permeability from the core measurements yielded two different estimates of the vertical distribution of permeability. Statistics from these estimates were used in the sub-problem concerned with estimating Rayleigh numbers and 
critical values thereof for our Perth Basin problem (Section 4).

\subsection{Background and induced flows}

There appear to be three dominant factors affecting the movement of water in the aquifer in the vicinity of the geothermal extraction system. To get an idea of the times and fluid speeds involved we considered the following:

1. the flow of water under gravity from the collection point up the Darling Escarpment to the sea;

2. the flow of water between a takeoff well and the associated reinjection well caused by pumping;

3. the flow of water within postulated convection cells.

For 1: We considered a water particle that infiltrates the aquifer via the Darling Fault and then flows underground a distance D $=30 \mathrm{~km}$ to the coast in the west, in the process losing about $\Delta \mathrm{h}=150 \mathrm{~m}$ in elevation corresponding to a loss of hydraulic head of $150 \mathrm{~m}$. Using an estimated average aquifer permeability of $\mathrm{K}_{\mathrm{H}}=0.1$ Darcy $=0.98 \times 10^{-13} \mathrm{~m}^{2}$, and the density and viscosity of water at a mean value of $60^{\circ} \mathrm{C}$ (see below for further parameter estimates), we can calculate the average Darcy velocity or specific discharge, $\mathbf{u}$, using Darcy's law:

$$
u=\frac{K_{H}}{\mu_{f}} \frac{\Delta p}{D}=\frac{K_{H}}{\mu_{f}} \frac{\rho_{f} g \Delta h}{D} .
$$

With the parameters above and as specified in Table 1 this gives velocity $u \approx 1.1 \times 10^{-8} \mathrm{~m} \mathrm{sec}^{-1}$. The interstitial speed $v$ of the fluid depends on the (dimensionless) matrix porosity $\phi$. With an estimated value of $\phi=0.1$ this gives $v \approx 3.4 \mathrm{~m} \mathrm{yr}^{-1}$; it would take about 9,000 years to complete the $30 \mathrm{~km}$ journey!

For 2: If 'waste' fluid from a geothermal energy installation was to be pumped into an aquifer of thickness $\mathrm{H}$ and porosity $\phi$ at a volumetric rate $f$ then after 
time $t$ the volume of injected fluid would fill the pore space in a cylinder of radius

$$
R=\sqrt{\frac{f t}{\phi \pi \mathrm{H}}} .
$$

If the fluid had been withdrawn from the aquifer at a rate that corresponds to a thermal load of $\mathrm{P}_{\text {th }}=10 \mathrm{MW}_{\text {th }}$ found by reducing the water temperature from $60^{\circ} \mathrm{C}$ to $35^{\circ} \mathrm{C}\left(\Delta \mathrm{T}=25^{\circ} \mathrm{C}\right)$, the water mass flow is calculated using

$$
\mathrm{P}_{\text {th }}=f \rho_{\mathrm{f}} \mathcal{c}_{\mathrm{P}} \Delta \mathrm{T},
$$

which gives a volume flow rate of $f \approx 0.1 \mathrm{~m}^{3} \mathrm{~s}^{-1}$; that is about 100 liters per second. With this water reinjection rate from an injection well into a system with thickness $\mathrm{H}=1800 \mathrm{~m}$ and porosity $\phi=0.1$, after one year the waste fluid would have penetrated from the well axis to a radius $R=75 \mathrm{~m}$, calculated using (1), with the fluid speed at the cylindrical front being about

$$
v=\frac{u(R)}{\phi}=\frac{f}{2 \pi R H \phi},
$$

which gives approximately $37 \mathrm{~m} \mathrm{yr}^{-1}$ at that time. This speed is significantly greater than the estimated natural flow calculated in (1), so the injected fluid would be likely to penetrate the aquifer 'upstream' against the natural slow current.

Now for 3: This is a more complex situation, which will be dealt with in some detail below. A rough estimate may be made of the upper limit for thermally driven convective fluid speed by considering the maximum pressure difference near the base of the system due to the difference in weights of two fluid columns, one at the minimum temperature of about $40^{\circ} \mathrm{C}$ and the other at $80^{\circ} \mathrm{C}$. If the columns are a distance $\mathrm{L}$ apart where $\mathrm{L}$ is approximately equal to the aquifer thickness $(1800 \mathrm{~m})$, then Darcy's law gives an estimate of the maximum horizontal Darcy speed at the base of the aquifer of

$$
u=\frac{K_{H}}{\mu_{f}} \frac{\Delta p}{L}=\frac{K_{H}}{\mu_{f}} \frac{\rho_{f}(40) g H-\rho_{f}(80) g H}{L},
$$


which gives $u \approx 1.4 \mathrm{myr}^{-1}$ corresponding to an interstitial speed of $v=$ $14 \mathrm{~m} \mathrm{yr}^{-1}$. Without knowing the location of the cell this could add to or subtract from the other fluid velocities. If the cell rotation is against the direction of motion of the injected cold water front, then there is little or no risk of contamination of the hot water extraction point from the re-injected cold water, at least at early times. If it is in the opposite direction, then there is near certainty that the extraction well will be contaminated with cooled water quite rapidly. Other planes of cell rotation will have intermediate consequences. Weak convective motion would certainly be disrupted by extraction and reinjection.

\section{Convective heat transfer in the aquifer}

Some effort was spent in attempting to determine whether the system was prone to convective instability. This would, according to theory and experiment, result in large scale convective 'rolls' of fluid motion that sought to augment the conductive heat transport. A series of aligned rolls, each in counter rotation to its neighbours, might induce hot spots or alignments near the ground surface, as well as cooler areas near the downflows.

\subsection{Convective instability}

The Perth Basin when heated from below is modelled as a Horton-RogersLapwood problem [3], see Figure 2. In this type of problem, the porous medium is assumed to be infinitely large in both horizontal directions, but bounded below (at $z=0$ ) and above (at $z=\mathrm{H}$ ) by impermeable seals. The top boundary is held at a constant temperature, $\mathrm{T}_{0}$, and the bottom boundary is held at temperature $T_{0}+\Delta T$, where $\Delta T>0$, so that the bottom boundary is always higher in temperature. 


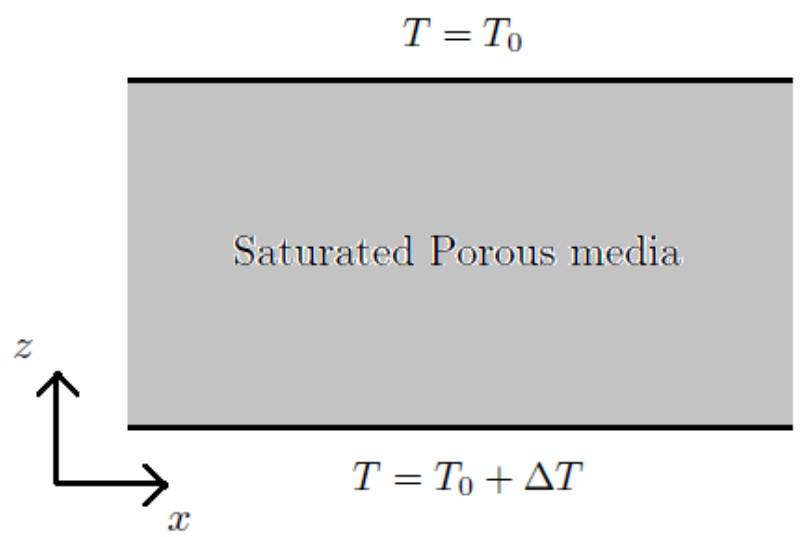

Figure 2: Schematic of the Horton-Rogers-Lapwood problem. The bottom boundary temperature is higher than at the top boundary.

The equations of conservation of mass, momentum and thermal energy that describe fluid and heat flow in a porous medium are (Nield \& Bejan [7])

$$
\begin{aligned}
\frac{\partial}{\partial t}\left(\phi \rho_{f}\right) & =-\nabla \cdot\left(\rho_{f} \mathbf{v}\right), \\
\mathbf{v} & =\frac{\mathbf{K}}{\mu_{f}} \otimes\left(-\nabla p+\rho_{f} \mathbf{g}\right), \\
\frac{\partial}{\partial t}\left[(1-\phi) \rho_{\mathrm{r}} u_{r}+\phi \rho_{f} u_{f}\right] & =-\nabla \cdot\left(\rho_{f} h_{f} \mathbf{v}-k_{m} \nabla T\right),
\end{aligned}
$$

where the second (momentum) equation is known as Darcy's Law. The parameters and variables are listed, together with their sI units, in Appendix A on nomenclature. The temperature dependence of the fluid thermodynamic properties are approximated locally by

$$
\begin{aligned}
\rho_{f}=\rho_{f}(T) & \approx \rho_{0}\left[1-\beta_{0}\left(T-T_{0}\right)\right], \\
\mu_{f}=\mu_{f}(T) & \approx \mu_{f}\left(T_{0}\right)\left(=\mu_{0}\right), \\
(1-\phi) \rho_{r} u_{r}+\phi \rho_{f} u_{f} & \approx(\rho c)_{m}\left(T-T_{0}\right), \\
k_{m} & \approx(1-\phi) k_{r}+\phi k_{f},
\end{aligned}
$$




$$
h_{\mathrm{f}} \approx c_{\mathrm{P}}\left(\mathrm{T}-\mathrm{T}_{0}\right) .
$$

Here, values subscripted "0" are those at the reference temperature $T_{0}$, while other parameters are taken to be constants. With the Boussinesq approximation, where the variation of fluid density with temperature is neglected except in the buoyancy term in Darcy's law, and the effect of variation of viscosity is assumed negligible, the equations for two dimensional flow $v(x, z, t)=(u, 0, w)$, where $u=u(x, z, t)$ and $w=w(x, z, t)$ are the horizontal and vertical velocity components with reference to the Cartesian axes $(x, y, z)$, where $z$ is vertical, become

$$
\begin{aligned}
\frac{\partial u}{\partial x}+\frac{\partial w}{\partial z} & =0 \\
u & =\frac{K_{H}}{\mu_{0}}\left(-\frac{\partial p}{\partial x}\right) \\
w & =\frac{K_{V}}{\mu_{0}}\left(-\frac{\partial p}{\partial z}-\rho_{0}\left[1-\beta_{0}\left(T-T_{0}\right] g\right),\right. \\
(\rho c)_{m} \frac{\partial T}{\partial t}+\rho_{0} c_{P}\left(u \frac{\partial T}{\partial x}+w \frac{\partial T}{\partial z}\right) & =k_{m H} \frac{\partial^{2} T}{\partial x^{2}}+k_{m} v \frac{\partial^{2} T}{\partial z^{2}} .
\end{aligned}
$$

Introduction of a stream function $\psi(x, z, t)$ where velocities $\mathfrak{u}=\partial \psi / \partial z$ and $w=-\partial \psi / \partial x$ provides identical satisfaction of the continuity equation (5); each of the upper and lower boundaries is then a stream-surface where the stream function has a constant value. Elimination of the pressure $p$ and other substitutions give

$$
\begin{aligned}
\frac{\partial^{2} \psi}{\partial x^{2}}+\frac{K_{V}}{K_{H}} \frac{\partial^{2} \psi}{\partial z^{2}} & =-\frac{\rho_{0} g \beta_{0} K_{V}}{\mu_{0}} \frac{\partial T}{\partial x} \\
(\rho c)_{m} \frac{\partial T}{\partial t}+\rho_{0} c_{P}\left(\frac{\partial \psi}{\partial z} \frac{\partial T}{\partial x}-\frac{\partial \psi}{\partial x} \frac{\partial T}{\partial z}\right) & =k_{m H} \frac{\partial^{2} T}{\partial x^{2}}+k_{m} v \frac{\partial^{2} T}{\partial z^{2}} .
\end{aligned}
$$

To extract out the motionless conductive state $(\psi \equiv 0)$, with an associated temperature field $\mathrm{T}=\mathrm{T}_{\text {cond }}(z)=\mathrm{T}_{0}+(1-z / \mathrm{H}) \Delta \mathrm{T}$, write

$$
\mathrm{T}=\mathrm{T}_{0}+(1-z / \mathrm{H}) \Delta \mathrm{T}+\theta(x, z, \mathrm{t}) .
$$


The equations are non-dimensionalized and linearized, by first writing

$$
\begin{array}{r}
\theta(x, z, t)=\Delta T\left(e^{r \mathrm{r} \hat{\theta}}(\hat{x}, \hat{z})\right), \quad \psi(x, z, t)=\Delta \Psi\left(e^{r \hat{t}} \hat{\psi}(\hat{x}, \hat{z})\right), \\
\text { where } \quad \Delta \Psi=\frac{k_{m} V}{\rho_{0} c_{P}}, \quad x=H \hat{x}, \quad z=H \hat{z}, \quad t=\frac{(\rho c)_{m} H^{2}}{k_{m} V} \hat{t},
\end{array}
$$

and then neglecting non-linear terms. In dimensionless form, the equations become

$$
\begin{aligned}
\frac{\partial^{2} \hat{\psi}}{\partial \hat{x}^{2}}+\frac{1}{\xi} \frac{\partial^{2} \hat{\psi}}{\partial \hat{z}^{2}} & =-\operatorname{Ra} \frac{\partial \hat{\theta}}{\partial \hat{x}} \\
r \hat{\theta}-\frac{\partial \hat{\psi}}{\partial \hat{x}} & =\eta \frac{\partial^{2} \hat{\theta}}{\partial \hat{x}^{2}}+\frac{\partial^{2} \hat{\theta}}{\partial \hat{z}^{2}} .
\end{aligned}
$$

Here

$$
\mathrm{Ra}=\frac{\rho_{0} \mathrm{gc}_{\mathrm{P}} \beta_{0} H K_{V} \Delta T}{v_{0} k_{\mathrm{m} V}}, \text { with } v_{0}=\mu_{0} / \rho_{0},
$$

is the dimensionless Rayleigh number based on vertical permeability and thermal conductivity, whereas $\xi=K_{H} / K_{V}$ and $\eta=k_{m H} / k_{m V}$ are measures of the anisotropy in the system permeability and thermal conductivity.

Under the principle of exchange of stabilities, the transition from a motionless conductive solution to small scale convection occurs at a 'critical' condition where decay with time $(r<0)$ changes to growth $(r>0)$; this is found by setting $r=0$ :

$$
\begin{aligned}
\frac{\partial^{2} \hat{\psi}}{\partial \hat{x}^{2}}+\frac{1}{\xi} \frac{\partial^{2} \hat{\psi}}{\partial \hat{z}^{2}} & =-\operatorname{Ra}_{\mathrm{c}} \frac{\partial \hat{\theta}}{\partial \hat{x}} \\
\eta \frac{\partial^{2} \hat{\theta}}{\partial \hat{x}^{2}}+\frac{\partial^{2} \hat{\theta}}{\partial \hat{z}^{2}} & =-\frac{\partial \hat{\psi}}{\partial \hat{x}} .
\end{aligned}
$$

The critical value of Rayleigh number is denoted $\mathrm{Ra}_{\mathrm{c}}$. Persistent convection may occur only for $\mathrm{Ra}>\mathrm{Ra}_{\mathfrak{c}}$. For $\mathrm{Ra}<\mathrm{Ra}_{\mathfrak{c}}$, any disturbance will decay 
$(\mathrm{r}<0)$. A solution with horizontal period $2 \hat{\mathrm{L}}$, corresponding to pairs of counter-rotating 'rolls' each of dimensionless lateral width $\hat{\mathrm{L}}=\mathrm{L} / \mathrm{H}$, is

$$
\begin{aligned}
\hat{\theta}(\hat{x}, \hat{z}) & =a \sin \left(\frac{\pi \hat{x}}{\hat{\mathrm{L}}}\right) \sin (\pi \hat{z}), \\
\hat{\psi}(\hat{x}, \hat{z}) & =a \frac{\left(\eta \frac{\pi^{2}}{\hat{\mathrm{L}}^{2}}+\pi^{2}\right)}{\frac{\pi}{\hat{\mathrm{L}}}} \cos \left(\frac{\pi \hat{x}}{\hat{\mathrm{L}}}\right) \sin (\pi \hat{z}), \\
\text { with } \quad \operatorname{Ra}_{\mathrm{c}}(\hat{\mathrm{L}}) & =\left(1+\frac{\hat{\mathrm{L}}^{2}}{\xi}\right)\left(1+\frac{\eta}{\hat{\mathrm{L}}^{2}}\right) \pi^{2} .
\end{aligned}
$$

The minimum value of the critical Rayleigh number with corresponding cell-width are

$$
\mathrm{Ra}_{\mathrm{c}}=(1+\sqrt{\eta / \xi})^{2} \pi^{2}, \quad \hat{\mathrm{L}}=\hat{\mathrm{L}}_{\mathrm{c}}=(\xi \eta)^{1 / 4} .
$$

In the Horton-Rogers-Lapwood problem as stated above, the minimum critical Rayleigh number for an isotropic layer $(\xi=\eta=1)$ is $\operatorname{Ra}_{c}=4 \pi^{2}$ for a cell-width $\hat{\mathrm{L}}=\hat{\mathrm{L}}_{\mathrm{c}}=1$.

For horizontally layered systems, the induced anisotropy in permeability is $\xi>1$, and the critical Rayleigh number is then reduced. Under such circumstances the width of a typical convection roll is greater than its height.

\subsection{The isotropic model}

Using parameters suitable for the Perth Basin, the Rayleigh number is calculated to determine if convection is likely to occur. Firstly, with the assumption that the permeability and thermal conductivity are isotropic, the parameters used were $c_{P}=4200 \mathrm{~J} \mathrm{~kg}^{-1} \mathrm{~K}^{-1}, \mathrm{~g}=9.81 \mathrm{~m} \mathrm{~s}^{-1}, \Delta \mathrm{T}=40 \mathrm{~K}, \mathrm{H}=$ $1800 \mathrm{~m}$ (Gage $200 \mathrm{~m}+$ Yarragadee $1000 \mathrm{~m}+$ Cadda $600 \mathrm{~m}$ ), $\mathrm{K}=10^{-13} \mathrm{~m}^{2}$, (a representative value, as it varies greatly with depth; see further below), $\mathrm{k}_{\mathrm{m}}=2.5 \mathrm{~W} \mathrm{~m}^{-1} \mathrm{~K}^{-1}, \mathrm{Ra}_{\mathrm{c}}=4 \pi^{2} \approx 39.5$. 
TABLE 1: Thermodynamic properties and calculated Rayleigh numbers for different reference temperatures $T_{0}$.

\begin{tabular}{rcccc}
\hline $\begin{array}{r}\mathrm{T}_{0} \\
{ }^{\circ} \mathrm{C}\end{array}$ & $\begin{array}{c}\beta_{0} \\
10^{-3} \mathrm{~K}^{-1}\end{array}$ & $\begin{array}{c}\rho_{0} \\
\mathrm{~kg} \mathrm{~m}^{-3}\end{array}$ & $\begin{array}{c}v_{0} \\
10^{-7} \mathrm{~m}^{2} \mathrm{~s}^{-1}\end{array}$ & $\mathrm{Ra}$ \\
\hline 20 & 0.2 & 998 & 9.8 & 24.2 \\
30 & 0.3 & 995 & 7.87 & 45.0 \\
40 & 0.38 & 992 & 6.43 & 69.6 \\
50 & 0.45 & 988 & 5.42 & 97.3 \\
60 & 0.51 & 983 & 4.6 & 129 \\
80 & 0.63 & 972 & 3.43 & 212 \\
100 & 0.65 & 957 & 2.9 & 255 \\
\hline
\end{tabular}

The results indicate that Rayleigh numbers are supercritical for temperatures $30^{\circ} \mathrm{C}$ and above. This is promising, as we are interested in temperatures above $40^{\circ} \mathrm{C}$. However, this is no guarantee that convection occurs in the Perth Basin, as the aquifer is heterogeneous, with horizontal layers, whereas in the Horton-Rogers-Lapwood problem, the porous medium is assumed to be homogeneous. A model which takes into account the horizontal layering is considered next.

\subsection{The anisotropic model}

According to the observational data taken from the Cockburn 1 well, the permeability of the rock matrix varies greatly as a function of depth. As a first approximation, the Perth Basin is modelled as a sequence of $\mathrm{N}$ superposed layers, each of uniform thickness $h_{i}$; the layered system is of total thickness $H$, with an impermeable seal at the top and bottom. Each of the layers has different values for permeability $\mathrm{K}_{i}$ and thermal conductivity $k_{m i}$; here, both parameters are assumed isotropic within each layer. This model of a system of homogeneous, isotropic layers is further simplified into a homogeneous, anisotropic medium if the thicknesses of the layers are all small compared 
to the total thickness. In this anisotropic model, the averaged horizontal and vertical permeabilities are different. These values are determined by considering uniform horizontal and vertical flow, and using Darcy's law to calculate the effective horizontal and vertical permeabilities. Similarly, the effective vertical conductivities can be determined by considering uniform heat flux through the medium (e.g. McKibbin [5]). This gives

$$
\overline{\mathrm{K}}_{\mathrm{H}} \mathrm{H}=\sum_{i=1}^{\mathrm{N}} \mathrm{K}_{\mathrm{i}} \mathrm{h}_{\mathrm{i}}, \quad \overline{\mathrm{k}}_{\mathrm{mH}} \mathrm{H}=\sum_{i=1}^{\mathrm{N}} \mathrm{k}_{\mathrm{i}} \mathrm{h}_{\mathrm{i}}, \quad \frac{\mathrm{H}}{\overline{\mathrm{K}}_{\mathrm{V}}}=\sum_{i=1}^{\mathrm{N}} \frac{\mathrm{h}_{\mathrm{i}}}{\mathrm{K}_{\mathrm{i}}}, \quad \frac{\mathrm{H}}{\overline{\mathrm{k}}_{\mathrm{mV}}}=\sum_{i=1}^{\mathrm{N}} \frac{\mathrm{h}_{\mathrm{i}}}{\mathrm{K}_{\mathrm{i}}},
$$

where the $\mathrm{H}$ and $\mathrm{V}$ subscripts denote horizontal and vertical. The overall average anisotropy in each property is expressed by the ratios

$$
\xi=\frac{\overline{\mathrm{K}}_{\mathrm{H}}}{\overline{\mathrm{K}}_{\mathrm{V}}} \text { and } \eta=\frac{\overline{\mathrm{k}}_{\mathrm{mH}}}{\overline{\mathrm{K}}_{\mathrm{mV}}} \text {. }
$$

As displayed in (14), the critical Rayleigh number and associated cell-width depend on the anisotropy. The Nusselt number $\mathrm{Nu}$ is an important dimensionless parameter for the problem. It measures the ratio of total heat transferred to the amount of heat transferred purely by conduction. For $\mathrm{Ra}<\mathrm{Ra}_{\mathrm{c}}$, $\mathrm{Nu}$ equals unity, as convection does not occur. For values of $\mathrm{Ra} / \mathrm{Ra}_{\mathrm{c}}$ not too much larger than unity, theory indicates that

$$
\mathrm{Nu}=1+2\left(\frac{\mathrm{Ra}}{\mathrm{Ra}_{\mathrm{c}}}-1\right) ;
$$

associated with supercritical conditions is an enhancement of the heat transfer. The general trend is shown in Figure 3. Results from a perturbation analysis are shown in Figure 4; the relationship is not linear when $\mathrm{Ra} / \mathrm{Ra}_{\mathrm{c}}$ is much larger than unity. With this information, it is now possible to determine whether or not convection is likely to occur in Perth's stratified aquifer. Using the same thermal and geometric parameters as earlier but with the average horizontal and vertical permeabilities and thermal conductivities different, and with

$$
\overline{\mathrm{K}}_{\mathrm{V}}=3.61 \times 10^{-14} \mathrm{~m}^{2}, \quad \xi=\frac{\overline{\mathrm{K}}_{\mathrm{H}}}{\overline{\mathrm{K}}_{\mathrm{V}}}=4.61,
$$




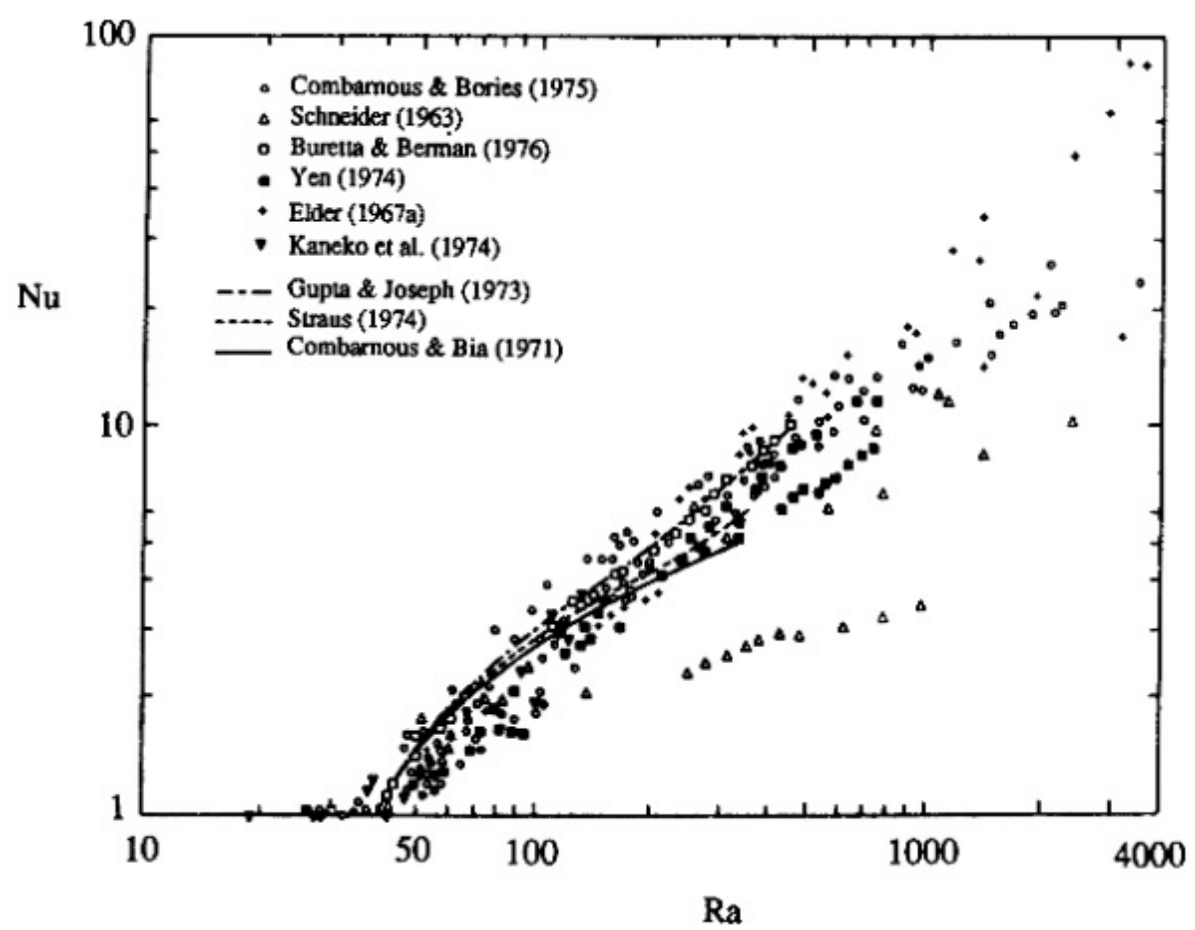

Figure 3: Trend of Nusselt number Nu with Rayleigh number Ra; compilation of results from various theoretical and experimental studies (Nield and Bejan [7]). 


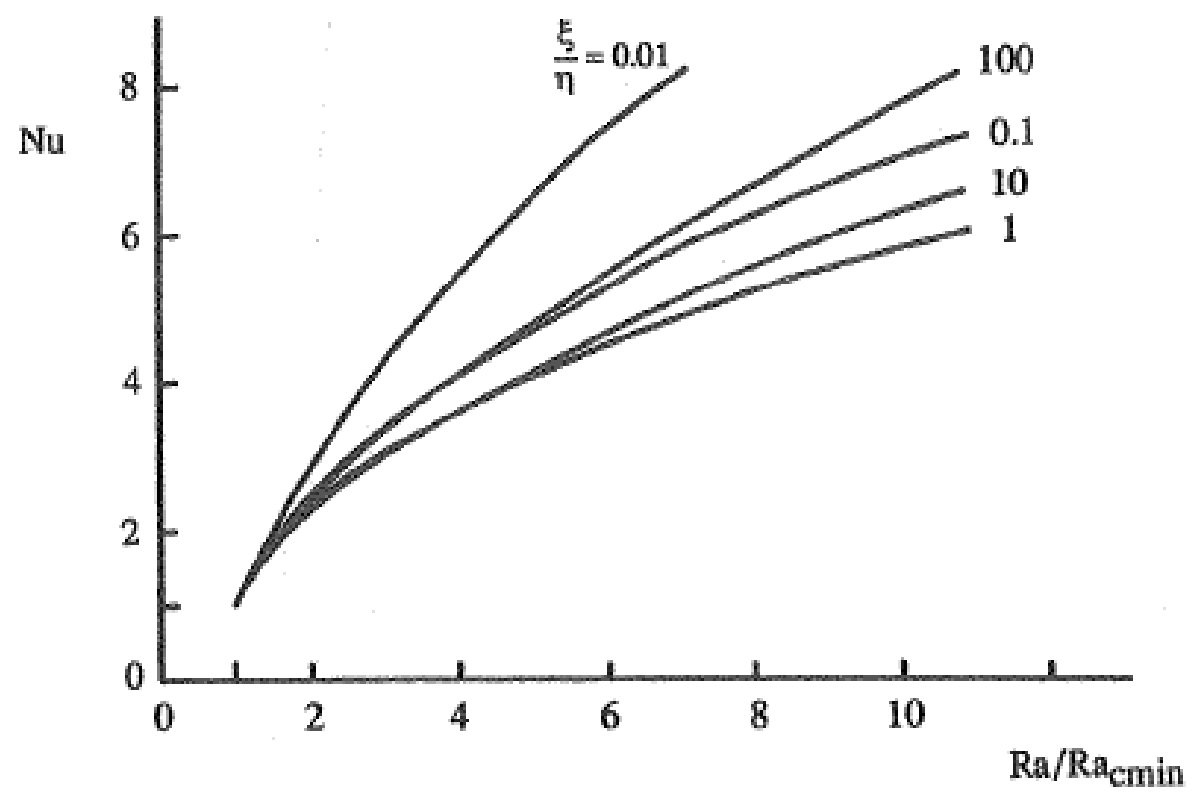

FiguRE 4: Nusselt number verses $\mathrm{Ra} / \mathrm{Ra}_{\mathrm{cmin}}$ from a theoretical study of homogeneous, anisotropic systems (McKibbin [5]; after Kvernvold \& Tyvand [2]). All plots start at $(1,1)$ with an initial slope of two. However, depending on the ratio of anisotropies $\xi / \eta$, the slope changes with increasing Ra. 
TABLE 2: Thermodynamic properties and calculated Rayleigh and Nusselt numbers with horizontal layering for different reference temperatures $T_{0}$.

\begin{tabular}{|c|c|c|c|c|c|}
\hline $\begin{array}{l}\mathrm{T}_{0} \\
{ }^{\circ} \mathrm{C}\end{array}$ & $\begin{array}{c}\beta_{0} \\
10^{-3} \mathrm{~K}^{-1}\end{array}$ & $\begin{array}{c}\rho_{0} \\
\mathrm{~kg} \mathrm{~m}^{-3}\end{array}$ & $\begin{array}{c}v_{0} \\
10^{-7} \mathrm{~m}^{2} \mathrm{~s}^{-1}\end{array}$ & $\mathrm{Ra}$ & $\mathrm{Nu}$ \\
\hline 20 & 0.20 & 998 & 9.80 & 8.5 & \\
\hline 30 & 0.30 & 995 & 7.87 & 15.8 & \\
\hline 40 & 0.38 & 992 & 6.43 & 24.2 & 1.2 \\
\hline 50 & 0.45 & 988 & 5.42 & 34.2 & 2.1 \\
\hline 60 & 0.51 & 983 & 4.60 & 45.4 & 2.5 \\
\hline 80 & 0.63 & 972 & 3.43 & 74.4 & 3.2 \\
\hline 100 & 0.65 & 957 & 2.90 & 89.4 & 3.7 \\
\hline
\end{tabular}

the vertical and horizontal permeabilities were calculated from a data set given in histogram form. In this case the permeabilities are weighted by the frequency of occurrence as a surrogate for layer thickness. The distribution of all permeabilities measured from core in the Perth Basin is shown in Figure 5. Figure 6 is the histogram of the permeability estimates from well logs in Cockburn 1 used in constructing the surrogate. The new critical Rayleigh value becomes $\mathrm{Ra}_{\mathrm{c}}=21.6$ with a corresponding dimensionless cell-width $\hat{\mathrm{L}}=1.49$. Table 2 lists the results of Rayleigh number calculations for various temperatures.

Thus, according to the Rayleigh numbers, it is entirely plausible that in the temperature regime of the aquifer $\left(40^{\circ} \mathrm{C}\right.$ and above), convection will occur.

\section{Detection of convection}

If convection cells exist, then it would be useful to drill in an upwelling zone where temperature levels are greatest (see schematic in Figure 7); drilling 


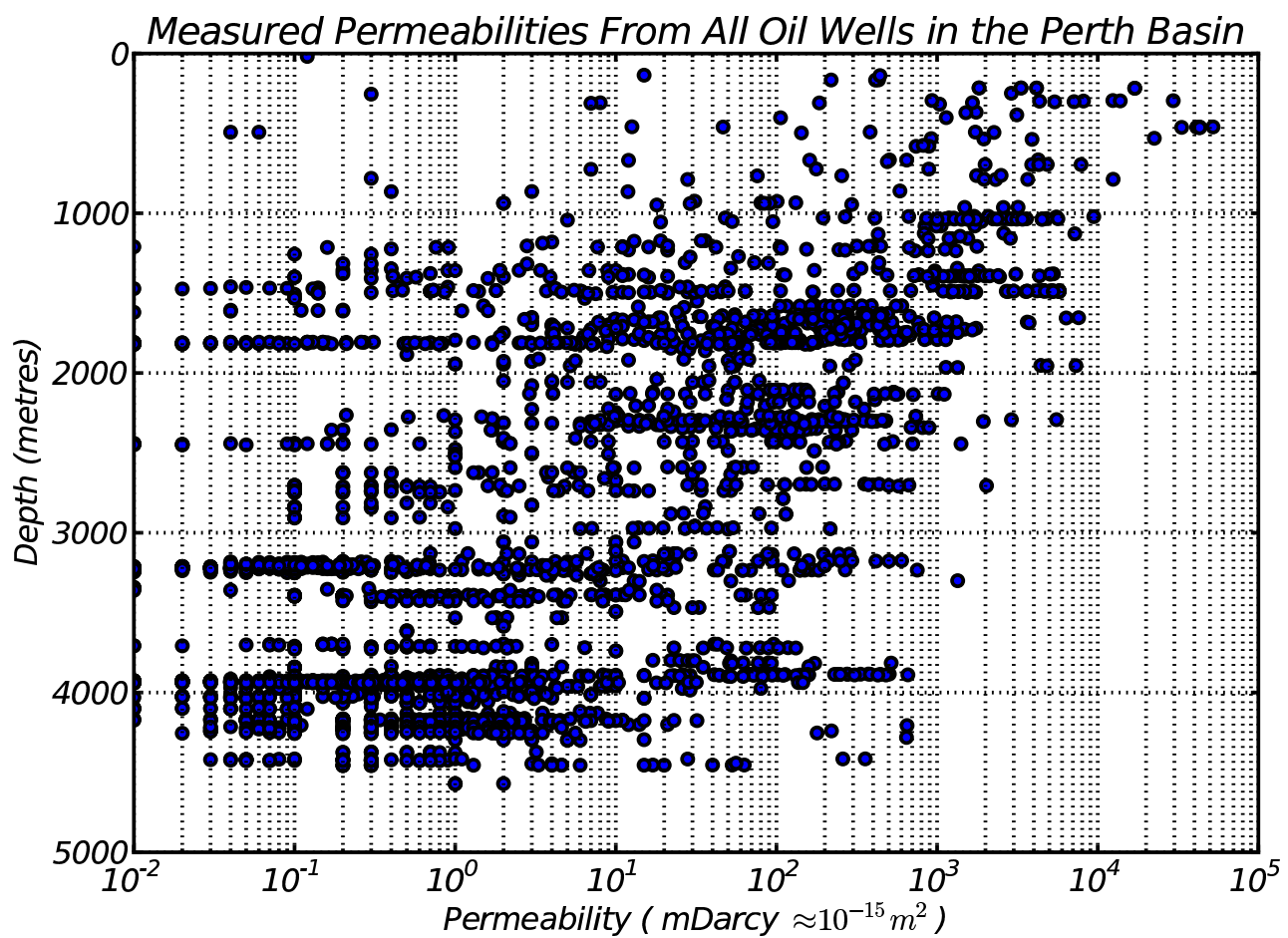

Figure 5: Measured permeabilities verses depth from wells in the Perth Basin. 


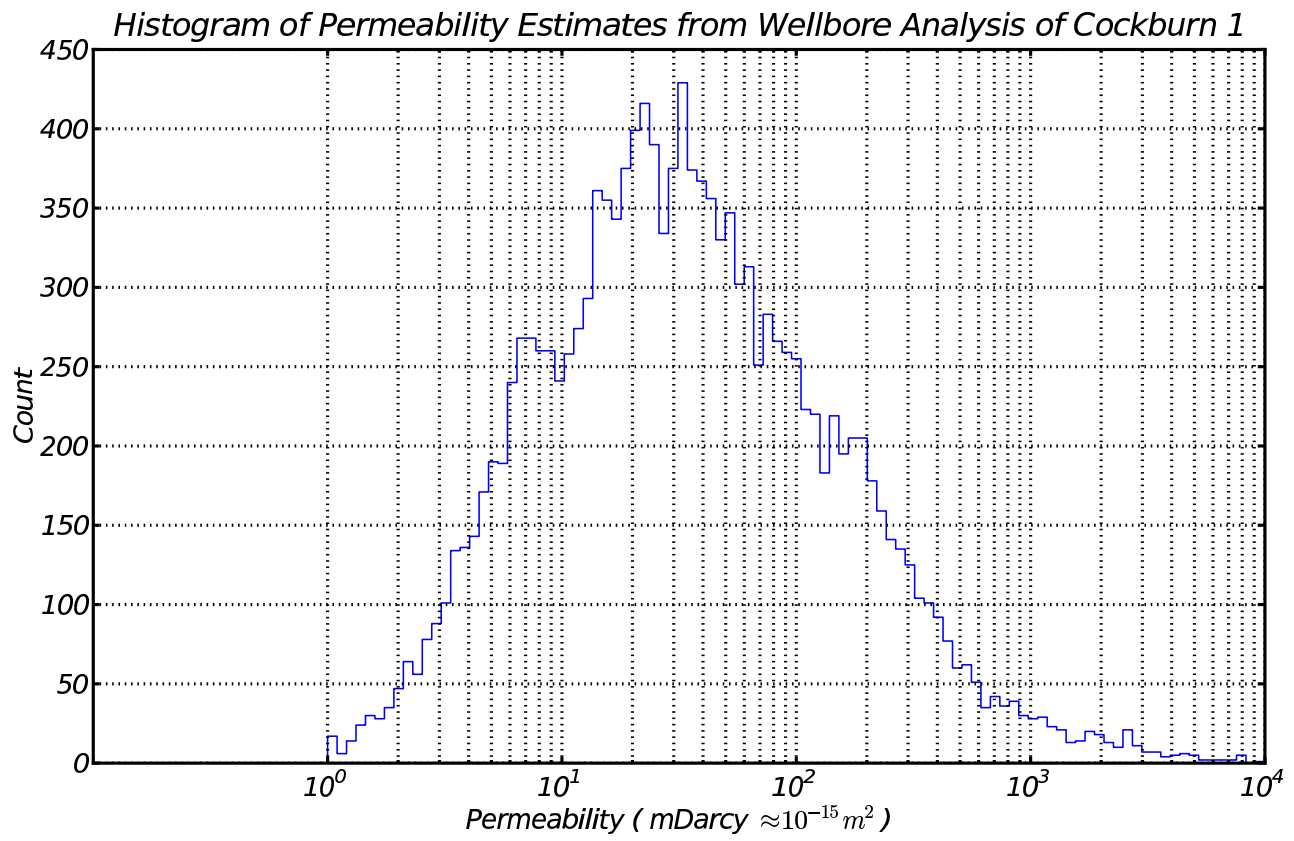

Figure 6: Permeability histogram. 


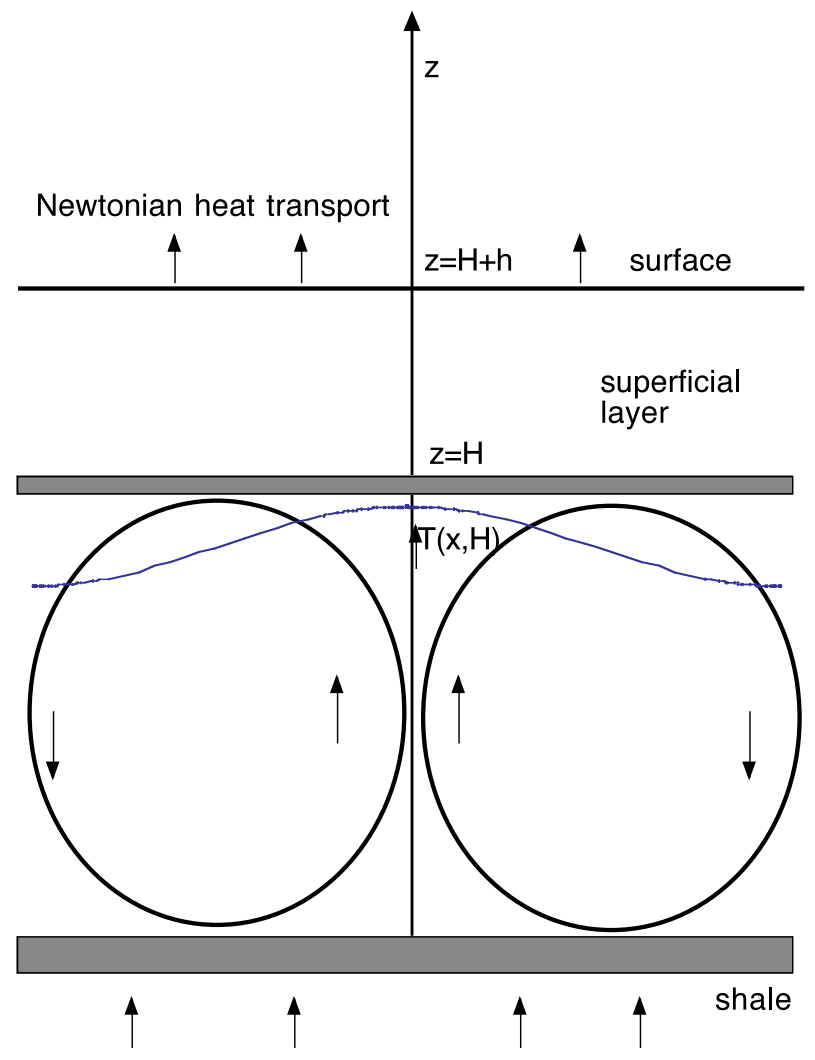

Figure 7: Surface detection of convection cells. Schematic of longitudinal rolls in the permeable aquifer beneath a confining stratum, with an example perturbed isotherm near the top of the convection region. 
costs could be significantly reduced. In order to do this one needs to be able to detect the presence and location of convection cells, which one might be able to do by measuring the temperature at or near the Earth's surface. Ideally, satellite temperature measurements may be used, but if this is not possible then evaluation of near-surface temperature or heat flux levels might be attempted using data from shallow drill holes.

To investigate the possibility of surface detection a simple heat transfer model was examined to determine the 'signal loss' when surface observations of temperature and flux are made, assuming that $R a>R_{c}$ so that convection is occurring in the permeable zone below the superficial layer. Given the depth of the cellular zone and the strength of the underlying heat source one would expect the superficial layer's thermal response to be secondary to that of the lower layers. Also at the Earth's surface the thermal response is strongly influenced by the thermal input from the sun, the radiative loss from the surface, along with evapotranspiration and advective meteorological exchanges. Subject to these dominant heat exchanges the superficial zone can only act passively; at least this seems a sensible assumption. For Rayleigh numbers just above the critical value the $2 \mathrm{D}$ rolls are generated and the temperature distribution in the (steadily and slowly) convecting layer is written (from (12), using (8)) in dimensional form as

$$
\mathrm{T}(x, z)=\mathrm{T}_{0}+\left(1-\frac{z}{\mathrm{H}}\right) \Delta \mathrm{T}+\mathrm{a} \Delta \mathrm{T} \sin \left(\frac{\pi z}{\mathrm{H}}\right) \sin \left(\frac{\pi \chi}{\mathrm{L}}\right),
$$

where $\mathrm{H}$ is the thickness of the layer and $\mathrm{L}$ is the cell-width, see Figure 7 . The dimensionless amplitude $a$ is known to be of order $\sqrt{\left(R a-R a_{c}\right) / R a_{c}}$ (e.g. Nield \& Bejan [7]). Under steady conditions, the equation for thermal conduction in the superficial layer is

$$
\eta_{s} \frac{\partial^{2} \mathrm{~T}}{\partial x^{2}}+\frac{\partial^{2} \mathrm{~T}}{\partial z^{2}}=0, \quad \mathrm{H}<z<\mathrm{H}+\mathrm{h},
$$

where $\eta_{S}$ is the average anisotropy in the thermal conductivity of the nearsurface materials. We assume that the thermal conductivity is isotropic there, so $\eta_{S}=1$. The solution with horizontal period $2 \mathrm{~L}$ in a semi-infinite domain 
$z>\mathrm{H}$ is $\mathrm{T}(\mathrm{x}, z)=\mathrm{T}_{0}+\mathrm{a} \Delta \mathrm{T} \sin (\pi x / \mathrm{L}) e^{-\pi(z-\mathrm{H}) / \mathrm{L}}$; there is an exponential decay in the vertical direction over a distance of order $\mathrm{L}$, that is the cell size. The superficial layer is not of infinite extent but nevertheless we expect the length scale of temperature variations to be of this order. This scale might seem to be too large $(\mathrm{H}=1800 \mathrm{~m})$ but the penetration time scale involved here is millions of years. The depth of the superficial layers is about $600 \mathrm{~m}$ so this result suggests there will be little attenuation in the temperature variations over such a distance. However, there are significant heat exchanges across the Earth's surface, which might affect this result. To investigate this we model the surface exchange using the Robin condition

$$
-k_{m} \frac{\partial T}{\partial z}=\gamma\left(T-T_{a}\right) \quad \text { at } z=(H+h)^{-},
$$

where $T_{a}$ is the (long term average) ambient atmospheric temperature and $\gamma$ is the thermal exchange coefficient; a range of $\gamma^{\prime}$ s will be examined. The vertical heat flux into the superficial layer from the lower convection zone must match that out of this zone which requires

$$
\frac{\partial \mathrm{T}}{\partial z}\left(x, \mathrm{H}^{+}\right)=-\frac{\Delta \mathrm{T}}{\mathrm{H}}+\mathrm{a} \Delta \mathrm{T} \frac{\pi}{\mathrm{H}} \sin \frac{\pi x}{\mathrm{~L}},
$$

using equation (16), assuming there is no conductivity change across the interface.

The temperature field in the superficial layer is separated into a horizontally uniform component and a (horizontally) varying component

$$
\mathrm{T}(x, z)=\overline{\mathrm{T}}(z)+\mathrm{T}^{\prime}(x, z), \quad \mathrm{H} \leqslant z \leqslant \mathrm{H}+\mathrm{h},
$$

and the two components obtained using the defining equation (17) and the boundary conditions $(18,19)$ at the upper and lower boundaries. The 'uniform' component is

$$
\overline{\mathrm{T}}=\mathrm{T}_{\mathrm{a}}+\left(\mathrm{H}+\mathrm{h}+\frac{\mathrm{k}_{\mathrm{m}}}{\gamma}-z\right) \frac{\Delta \mathrm{T}}{\mathrm{H}},
$$


and is of no use for detection, with the more interesting horizontally varying component

$$
\mathrm{T}^{\prime}(x, z)=\mathrm{a} \Delta \mathrm{T}\left(\frac{\mathrm{L}}{\mathrm{H}}\right)\left[\frac{\cosh \frac{\pi(\mathrm{H}+\mathrm{h}-z)}{\mathrm{L}}+\frac{\gamma \mathrm{L}}{\pi \mathrm{k}_{\mathrm{m}}} \sinh \frac{\pi(\mathrm{H}+\mathrm{h}-z)}{\mathrm{L}}}{\sinh \frac{\pi h}{\mathrm{~L}}+\frac{\gamma \mathrm{L}}{\pi \mathrm{k}_{\mathrm{m}}} \cosh \frac{\pi h}{\mathrm{~L}}}\right] \sin \frac{\pi \chi}{\mathrm{L}} .
$$

Note, as anticipated earlier, the temperature variations on the Earth's surface are of order $\mathrm{a} \Delta \mathrm{T}$ (that is, of the same order as those within the convecting layer), but with a reduction in amplitude with elevation above the interface $z=\mathrm{H}$, see Figure 7 . The effect of the heat transfer coefficient $\gamma$ on the scaled amplitude of this variation can also be seen in Figure 7. Note that the effect of an increased $\gamma$ is to reduce the amplitude of temperature variation through the superficial layer. At the Earth's surface, the temperature and the flux associated with the fluctuating component are

$$
\mathrm{T}^{\prime}(x, H+h)=a \Delta T\left(\frac{\mathrm{L}}{\mathrm{H}}\right)\left[\frac{1}{\sinh \frac{\pi h}{\mathrm{~L}}+\frac{\gamma \mathrm{L}}{\pi k_{m}} \cosh \frac{\pi h}{\mathrm{~L}}}\right] \sin \frac{\pi x}{\mathrm{~L}},
$$

and

$$
-\mathrm{k}_{\mathrm{m}} \frac{\partial \mathrm{T}^{\prime}}{\partial z}(x, \mathrm{H}+\mathrm{h})=\mathrm{a} \Delta \mathrm{T}\left(\frac{\mathrm{L}}{\mathrm{H}}\right)\left[\frac{\gamma}{\sinh \frac{\pi \mathrm{h}}{\mathrm{L}}+\frac{\gamma \mathrm{L}}{\pi \mathrm{k}_{\mathrm{m}}} \cosh \frac{\pi \mathrm{h}}{\mathrm{L}}}\right] \sin \frac{\pi x}{\mathrm{~L}} .
$$

Thus in dimensionless form, (in our case $\hat{\mathrm{h}}=\mathrm{h} / \mathrm{H}=600 / 1800=0.33$ ) the fractional reductions in the amplitudes of these two 'signals' reaching the Earth's surface are

$$
\frac{T^{\prime}(\hat{x}, 1+\hat{h})}{T^{\prime}(\hat{x}, 1)}=\frac{1}{\cosh \frac{\pi \hat{\mathrm{L}}}{\hat{\mathrm{L}}}\left[1+\frac{\hat{\gamma} \hat{\mathrm{L}}}{\pi} \tanh \frac{\pi \hat{\mathrm{h}}}{\hat{\mathrm{L}}}\right]},
$$

and

$$
\frac{-k_{m} \frac{\partial T^{\prime}}{\partial \hat{z}}(\hat{x}, 1+\hat{h})}{-k_{m} \frac{\partial T^{\prime}}{\partial \widehat{z}}(\hat{x}, 1)}=\frac{1}{\cosh \frac{\pi \hat{\kappa}}{\hat{L}}\left[1+\frac{\pi}{\hat{\imath} \hat{\mathrm{L}}} \tanh \frac{\pi \hat{\kappa}]}{\hat{\mathrm{L}}}\right]}
$$




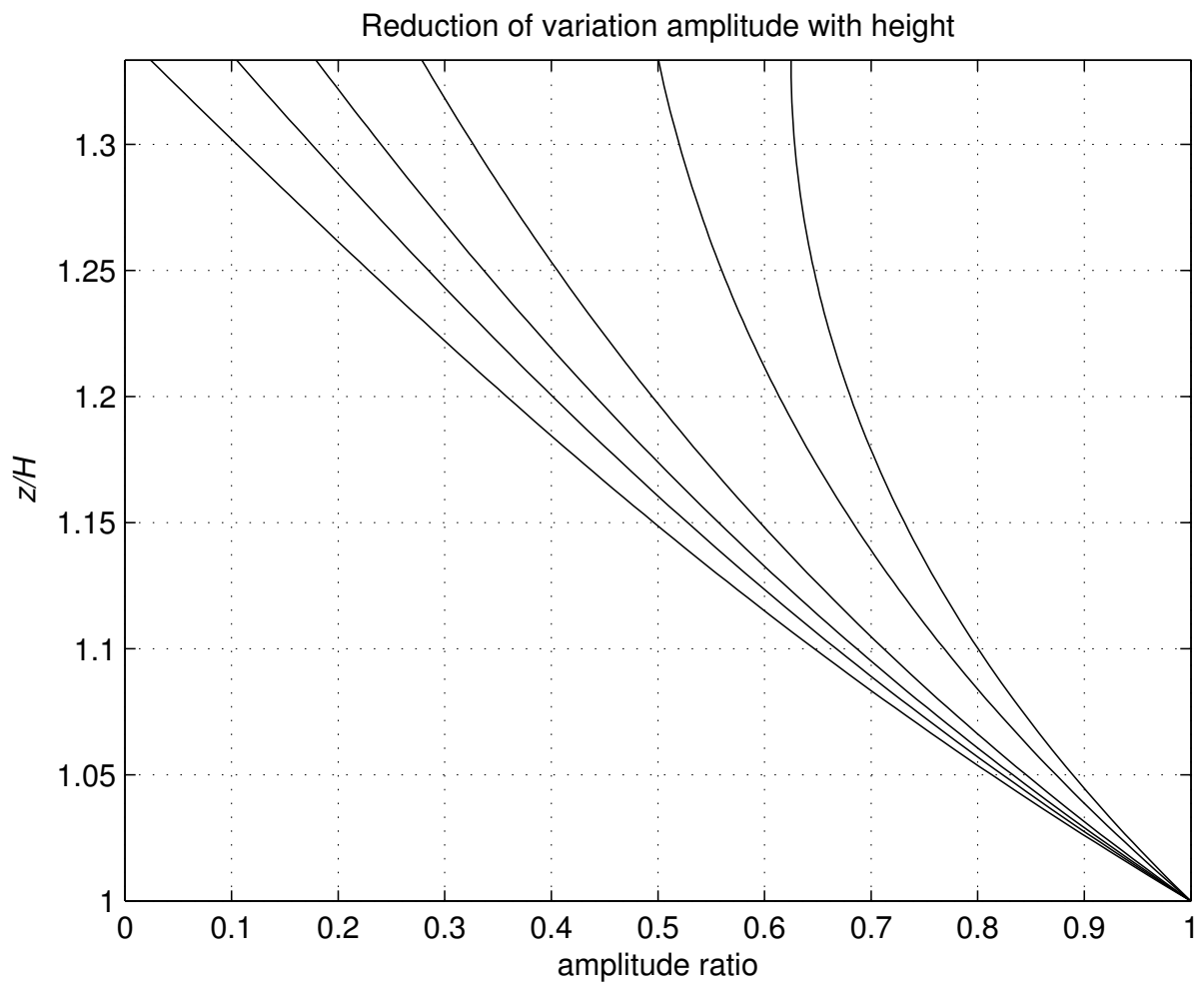

FIGURE 8: The temperature distribution amplitude, relative to its interface value, through the upper layer for $\hat{\gamma}=0$ (upper curve), 1, 5, 10, 20, 100 (lower curve) $(\hat{\mathrm{L}}=1, \hat{\mathrm{h}}=1 / 3)$. 


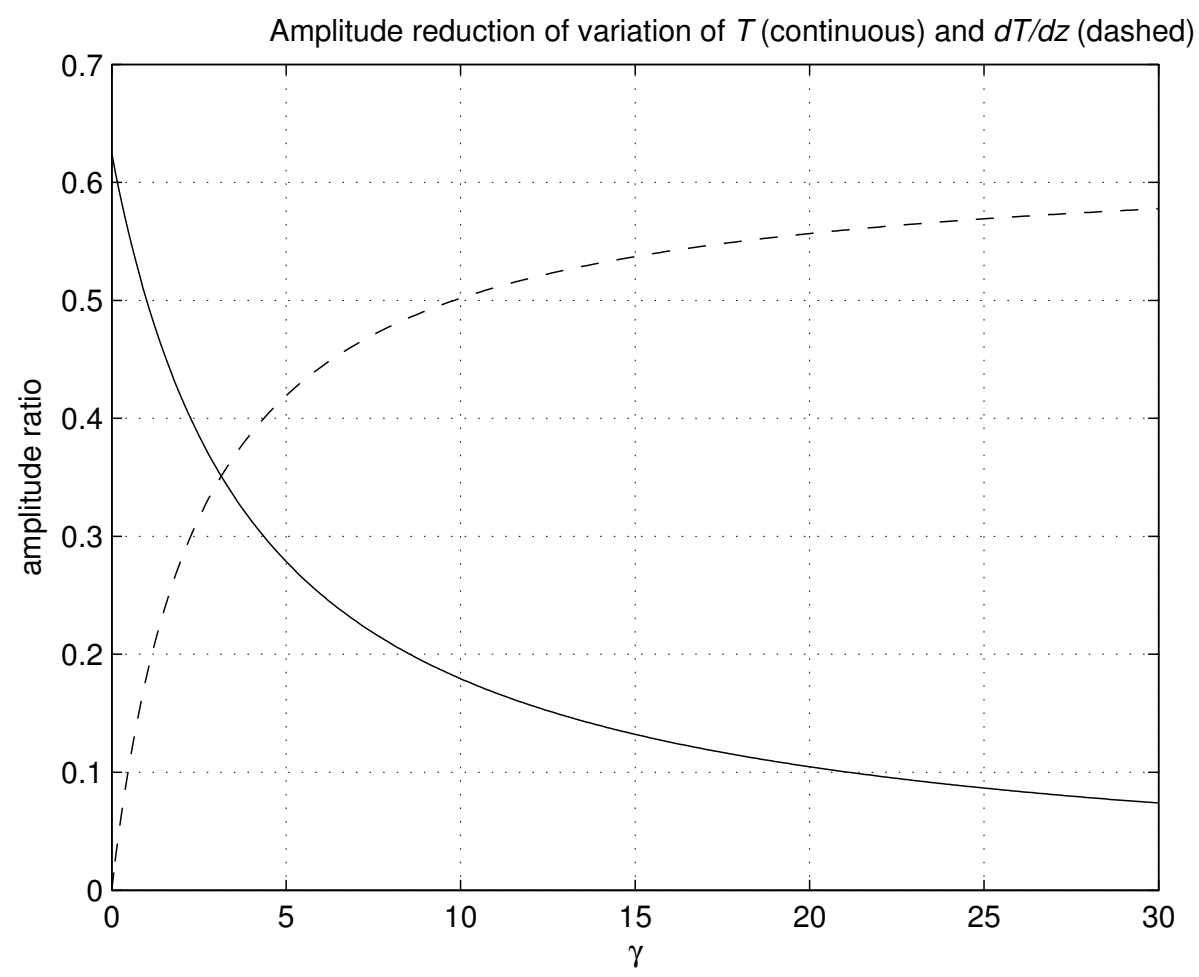

Figure 9: Surface temperature amplitude (continuous) and temperature gradient (dashed) variations relative to their interface values, as a function of the heat transfer coefficient $\hat{\gamma}(\hat{\mathrm{L}}=1, \hat{\mathrm{h}}=1 / 3)$.

where $\hat{\gamma}=\left(\mathrm{H} / \mathrm{k}_{\mathrm{m}}\right) \gamma$. Note that an increase in the heat transfer coefficient $\hat{\gamma}$ results in a smaller temperature variation on the surface but a larger flux variation, as can be seen in Figure 8. Note that $\hat{\gamma}=0$ corresponds to the (unrealistic) insulated surface limit. The scaled heat transfer coefficient will vary from location to location depending on surface conditions, and needs to be experimentally determined; however, Figure 9 suggests a reduction in amplitude of about $50-62 \%$ in our case where $\hat{\mathrm{h}}=1 / 3$. A schematic example of isotherm and stream-surface patterns is shown in Figure 10. The picture was constructed by knitting together the solution (16) in the permeable 


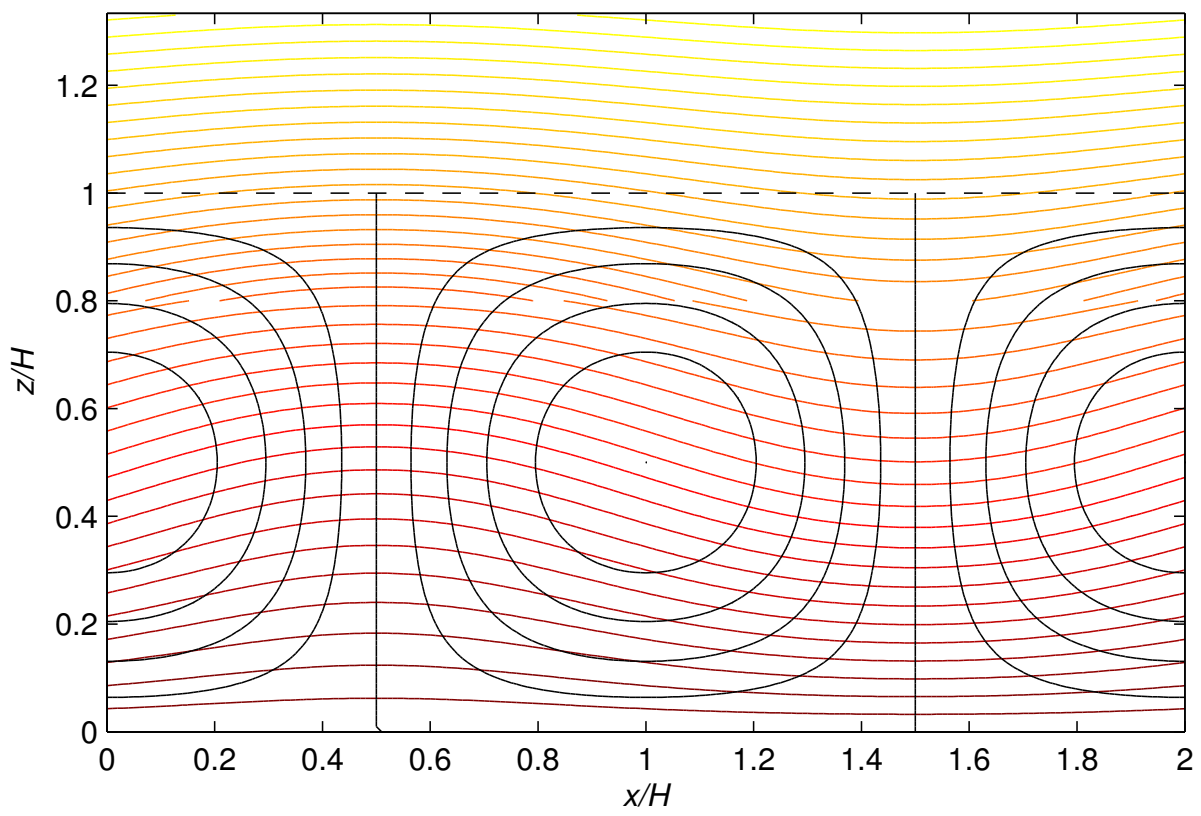

FiguRE 10: Example isotherms and stream-surfaces that correspond to small-amplitude convection rolls, for the case $\hat{\gamma}=1(\widehat{h}=1 / 3)$.

aquifer and the solution (21) for the conductive region. The temperatures do not match at the interface of the two regions, so the solution (21) has been allowed to overlap the lower region until it matches the temperature patterns in the convection zone. A more rigorous mathematical solution of the same order could be found by treating the two layers together (and matching both temperature and flux across the interface $z=\mathrm{H}$ ), perhaps as an inverted version to the system treated by McKibbin [4].

Thus for conditions of interest the temperature variations at the surface due to the presence of a convection zone will be reduced to about $40 \%$ (or less) of those present within the convection zone itself. However, at the Earth's surface there will be relatively large amplitude temperature variations superimposed on the above 'steady' variations due to solar exchanges. These variations of 
perhaps $20^{\circ} \mathrm{C}$ decay over a distance of order $\sqrt{\kappa / \omega}$ from the Earth's surface where $\omega$ is the frequency of the solar component of interest and $\kappa$ is the thermal diffusivity of the Earth's surface; daily variations penetrate to a distance of about $1 \mathrm{~m}$ whilst yearly variations penetrate about $16 \mathrm{~m}$. Longer term variations (e.g. solar variations of approximately $15 \mathrm{yr}$ ) penetrate still further but can be reasonably accounted for. By using drill holes of a few metres depth, daily variations are filtered out, leaving yearly and longer period variations to filter out. In general convection zone detection using surface or near-surface temperature measurements seems unlikely. However, it should be possible to distinguish a convection zone profile once the drill has penetrated some distance into the superficial layer.

\section{Conclusions}

The problem was tractable, but depended on suitable estimates of rock matrix properties from drill cores that were rather complex in structure. It also depended on good estimates of aquifer temperatures; the deeper values were elusive, and had to be deduced from extrapolations of shallow well measurements. However, by the end of the MISG week, the group felt it had a better understanding of the geothermal mechanisms at work in the Perth Basin and the issues that yet need to be resolved. Geothermal systems are complicated geological-geophysical-thermodynamical entities. A multi-disciplinary approach to understanding them is necessary. However, the quantification of their attributes is well handled by mathematically able scientists and the MISG proved a suitable venue to tackle the WAGCoE problem.

Acknowledgements The group for this project consisted of about a dozen people working at RMIT and another five 'at home' at UWA in Perth. Video links made three times during the study week via the Access Grid allowed exchange of information about hypotheses and progress. The use of such remote access may be usefully employed in future MISG's in order to enlarge 
working groups or to discuss particular issues with specialists who cannot attend the Study Group venue. Also, various documents were shared through a website set up at UWA. Useful journal articles, field data, written workings, records of progress and the Friday Report presentation are available on the internet. ${ }^{1}$

The project moderators Robert McKibbin, Nev Fowkes and Brendan Florio thank the industry representative from wAGCoE, Frank Horowitz, who actively participated in investigations before, during and after the MISG. The work party included the following enthusiastic geothermal groupies: Nicole Walters, Fleur McDonald, Luke Fullard, Nick Hale, Rob Style, Tony Gibb, Thiansiri Luangwilai (Pat), Nurul Syaza Abdul Latif, Manarah Eraki, Des Hill, Christian Thomas, Thomas Stemler, Grant Keady and Melanie Roberts.

\section{A Nomenclature}

Symbol Description and SI units

a amplitude of temperature variation [-]

$c_{P} \quad$ specific heat of water $\left[\mathrm{J} \mathrm{kg}^{-1} \mathrm{~K}^{-1}\right]$

$\mathrm{D} \quad$ aquifer length $[\mathrm{m}]$

$\mathrm{f} \quad$ fluid volume injection rate $\left[\mathrm{m}^{3} \mathrm{~s}^{-1}\right]$

g gravitational acceleration $\left[\mathrm{m} \mathrm{s}^{-2}\right]$

$\mathrm{H}$ permeable aquifer total thickness [m]

$\mathrm{h} \quad$ aquifer sub-layer thickness [m]

$h_{\mathrm{f}} \quad$ specific enthalpy of fluid $\left[\mathrm{kJ} \mathrm{kg}^{-1}\right]$

$\mathrm{k} \quad$ thermal conductivity $\left[\mathrm{W} \mathrm{m}^{-1} \mathrm{~K}^{-1}\right]$

$\mathrm{K}$ permeability $\left[\mathrm{m}^{2}\right]$

$\mathrm{L} \quad$ convection roll width $[\mathrm{m}]$

$\mathrm{N}$ number of sub-layers [-]

${ }_{1}^{1}$ http://school.maths. uwa.edu. au/ anziam/Geothermal/Convection/index. html 


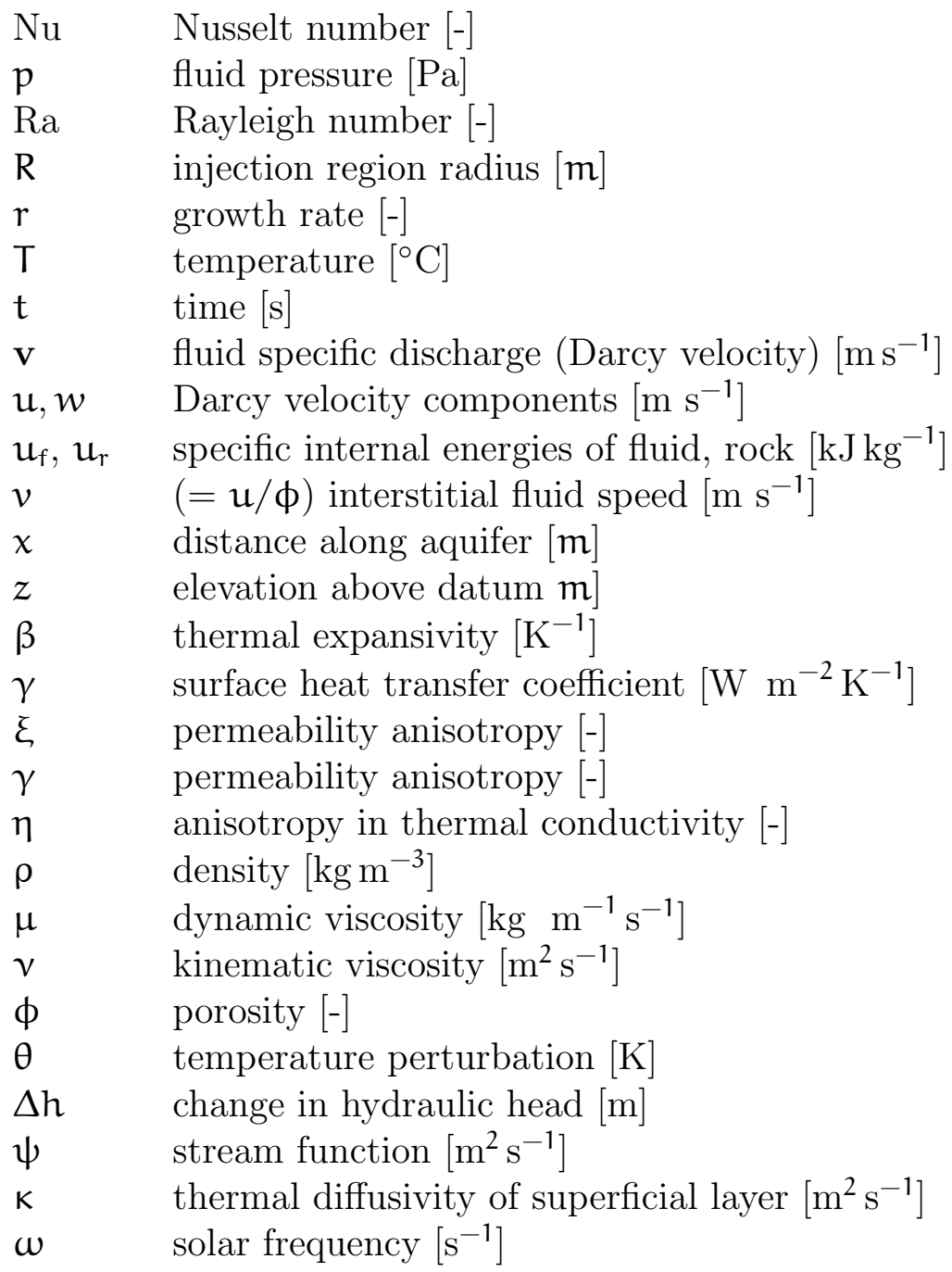

\section{Subscripts}

Symbol Description

0 reference value 


$\begin{array}{ll}H & \text { horizontal } \\ \text { m } & \text { mixture } \\ r & \text { rock matrix } \\ V & \text { vertical } \\ f & \text { fluid } \\ c & \text { critical } \\ \text { min } & \text { minimum } \\ i & \text { layer number } \\ \text { S } & \text { superficial layer } \\ \text { ^ } & \text { dimensionless quantity } \\ - & \text { average quantity }\end{array}$

\section{References}

[1] D. N. Smith, "Cockburn No. 1 Well, Western Australia, Well Completion Report", Western Australian Petroleum, Pty. Limited, October 1967. M9

[2] O. Kvernvold and P. A. Tyvand, "Nonlinear thermal convection in anisotropic porous media", J. Fluid Mech., 90, pp.609-624, 1979. M20

[3] E. R. Lapwood, "Convection of a fluid in a porous medium", Proc. Camb. Phil. Soc., 44, pp.508-521, 1948. M12

[4] R. McKibbin, "Convection in an aquifer above a layer of heated impermeable bedrock", NZ J. Sci., 26, pp.49-64, 1983. M30

[5] R. McKibbin, "Thermal convection in layered and anisotropic porous media: a review", In: Wooding, R. A. and I. White, (eds) "Convective Flows in Porous Media", Dept. Sci. Indust. Res., Wellington, New Zealand, pp.113-127, 1985. M18, M20 
[6] R. McKibbin, N. Hale, R. W. Style, and N. Walters, "Convection and heat transport in layered sloping warm-water aquifers", Journal of Porous Media, In press. M7

[7] D. A. Nield and A. Bejan, Convection in porous media, 3rd Edition, Springer, 2006. M13, M19, M25

[8] R. C. Ransom, Practical formation evaluation, Wiley, 1995. M9

[9] K. Regenauer-Lieb, H. T. Chua, X. Wang, F. G. Horowitz and J. Wellman, "Direct heat geothermal applications in the Perth Basin of Western Australia", Proc. 34th Annual Stanford Workshop on Geothermal Engineering, Chapter 14, Stanford University, California, 2009. M4

\section{Author addresses}

1. Robert McKibbin, Institute of Information and Mathematical Sciences, Massey University, Albany Campus, Auckland, NEW ZEALAND. mailto:R.McKibbin@massey .ac.nz

2. Neville Fowkes, School of Maths \& Stats, University of Western Australia, Crawley, Australia mailto: fowkes@maths . uwa. edu . au

3. Brendan Florio, School of Maths \& Stats, University of Western Australia, Crawley, Australia mailto: brendan@maths. uwa. edu . au

4. Franklin G. Horowitz, School of Earth \& Environment and WAGCoE, University of Western Australia, Crawley, Australia mailto:frank. horowitz@uwa.edu.au 